\title{
Influence of Benzenediols-Pyrocatechol and Resorcinol-On the Resistance of Portland Cement Mortars with Aluminum Sulfate to Sulfate Attack
}

\author{
Alexey Brykov¹, Natalia Paritskaya', Alexander Velichko', Maxim Mokeev² \\ ${ }^{1}$ Department of Chemistry of Substances and Materials, Saint-Petersburg State Institute of Technology, St. Petersburg, Russia \\ ${ }^{2}$ Institute of Macromolecular Compounds, St. Petersburg, Russia \\ Email: brykov@yahoo.com
}

How to cite this paper: Brykov, A., Paritskaya, N., Velichko, A. and Mokeev, M. (2018) Influence of Benzenediols-Pyrocatechol and Resorcinol-On the Resistance of Portland Cement Mortars with Aluminum Sulfate to Sulfate Attack. Materials Sciences and Applications, 9, 305-313.

https://doi.org/10.4236/msa.2018.92020

Received: January 5, 2018

Accepted: February 11, 2018

Published: February 14, 2018

Copyright ( 92018 by authors and Scientific Research Publishing Inc. This work is licensed under the Creative Commons Attribution International License (CC BY 4.0).

http://creativecommons.org/licenses/by/4.0/

\section{c) (i) Open Access}

\begin{abstract}
The effect of benzene-1,2-diol (pyrocatechol) and benzene-1,3-diol (resorcinol) on the development of sulfate attack in Portland cement mortars containing alkali-free setting accelerator (aluminum sulfate) was studied. It has been found that these compounds (especially pyrocatechol—due to its ability to form chelate complexes with aluminum ions) restrain destructive deformations of Portland cement mortars with aluminum sulfate admixture when under test conditions a constant supply of sulfate ions from external source is provided. According to ${ }^{27} \mathrm{Al}-\mathrm{MAS}$ NMR data, pyrocatechol does not influence the amount of ettringite formed in Portland cement paste during its store in sodium sulfate solution. Presumably, in presence of benzenediols, in cement mortars with aluminum sulfate admixture the formation of ettringite crystals with a less pronounced destructive effect takes place.
\end{abstract}

\section{Keywords}

Pyrocatechol, Benzenediols, Aluminum Sulfate, Portland Cement, Sulfate Attack, Ettringite, NMR Spectroscopy

\section{Introduction}

In modern formulations of Portland cement based building materials organic compounds are mainly presented as various water-soluble polymers that function as water-reducing, air-entraining, water-retaining and rheological agents [1]. At the same time quite a concern remains regarding low-molecular organic 
compounds in mortar and concrete applications. One of the classes of such compounds is represented by polyatomic phenols, in particular-diatomic phenols, or benzenediols (pyrocatechol, resorcinol, hydroquinone and their derivatives) [2] [3], due to its ability to form complex compounds with metal and silicon ions. Moreover, pyrocatechol (benzene-1,2-diol or 1,2-dihydroxybenzene), which has two hydroxide groups in ortho-position, can act as a bidentate ligand to form strong chelate (cyclic) complexes with central cation.

The relative position of the $\mathrm{OH}$-groups in benzenediols determines their activity to Portland cement: pyrocatechol is known as setting accelerator, resorcinol (benzene-1,3-diol or 1,3-dihydroxybenzene) has no significant effect on setting, hydroquinone (benzene-1,4-diol) has a retarding effect [4]. It was reported in [5] about the ability of pyrocatechol and other aromatic compounds with two hydroxyl groups in ortho-position to reduce setting time of Portland cement pastes, where a miniscule amount of pyrocatechol (0.02 - 0.03 mass\%) causes almost instantaneous setting.

In [6] [7] wastes of diatomic phenols production (resorcinol, pyrocatechol) have been studied as modifiers of cement mortars and concretes; it has been found that they possess high plasticizing properties with the effect comparable to the efficiency of commercially available superplasticizers. In [8] benzenediols-containing composition to control properties of Portland cement mortars and concretes is patented. Pyrocatechol and hydroquinone are proposed for introduction into clinker-grinding mills for reduction of hexavalent chromium [9].

Polyatomic phenols are present in a wastewater of oil refineries and coking plants, logging companies, pharmaceutical factories, they also can be found in high content in soils, due to pollution from industrial processing of fossil fuels, or formed by biological processes. The corrosive effect of these compounds on concrete has been discussed in [10] [11] [12].

Properties of cement compositions with addition of polyatomic phenols are mainly defined by their interaction with aluminum- and iron-containing phases of Portland cement clinker or its additives [5] [13]. Since even trace amounts of polyatomic phenols can cause noticeable effects upon Portland cement properties, this motivates the need for further research in this field. The purpose of the present work is to study influence of two benzenediol's isomers-pyrocatechol and resorcinol-on the development of sulfate attack in Portland cement mortars with aluminum sulfate admixture. Aluminum sulfate is a known alkaline-free setting accelerator, but its use in Portland cement concrete formulations can be obstructed by subsequent development of sulfate attack under favorable conditions [14].

\section{Experimental Part}

In this work, pyrocatechol and resorcinol purified by sublimation were used; pyrocatechol-colorless thin plates with melting point $\mathrm{Tm}$ of $98^{\circ} \mathrm{C}-104^{\circ} \mathrm{C}$ (reference data is $104^{\circ} \mathrm{C}$ ); resorcinol-colorless thin fibers with $\mathrm{Tm}$ of $109^{\circ} \mathrm{C}$ (refer- 
ence data is $\left.109^{\circ} \mathrm{C}-110^{\circ} \mathrm{C}\right)$.

Portland cement CEM I $42.5 \mathrm{~N}$ with the following composition, wt\%: $\mathrm{C}_{3} \mathrm{~S} 52$ $53, \mathrm{C}_{2} \mathrm{~S} 18-20, \mathrm{C}_{3} \mathrm{~A}+\mathrm{C}_{4} \mathrm{AF} 20$ - 22, gypsum $\left(\mathrm{CaSO}_{4} \cdot 2 \mathrm{H}_{2} \mathrm{O}\right) 3-4$, anhydrite (Ca$\left.\mathrm{SO}_{4}\right) 1, \mathrm{CaCO}_{3} 2$ was used. Granulated aluminum sulfate hydrate $\mathrm{Al}_{2}\left(\mathrm{SO}_{4}\right)_{3} \cdot 14 \mathrm{H}_{2} \mathrm{O}$ (ALG, "Kemira Oyj", $\mathrm{Al}_{2} \mathrm{O}_{3} 17.1 \mathrm{wt} \%$ ) was used as aluminum-bearing admixture. For sulfate resistance test ordinary quartz-feldspar sand with fineness modulus of 1.5 was used as mortar aggregate.

Dosages of pyrocatechol and resorcinol $(0.02 \% \div 0.1 \%$ by the cement weight) were chosen taken into account data from authors previous researches [13] [14].

Initial and final setting time of cement pastes with admixture of aluminum sulfate hydrate ( $3 \%$ by cement weight on dry basis), pyrocatechol and resorcinol ( $0.1 \%$ by cement weight) were determined in accordance with GOST 310.3 - 76 at water-to-cement ratio 0.4 (distilled water was used). The admixtures were preliminarily dissolved in mixing water; hydrate water of aluminum sulfate was taken into account to calculate total amount of water.

Effect of admixtures on sulfate resistance of mortars was studied by following the method close to that described in ASTM C 1012 "Length Change of Hydraulic-Cement Mortars Exposed to a Sulfate Solution”. A reference mortar mix was prepared by mixing cement with sand (at weight ratio of 1:2.75) and distilled water (water-to-cement ratio 0.485). Mortar mixes with addition of aluminum sulfate and benzenediols previously dissolved in the mixing water were similarly prepared. The amount of aluminum sulfate was $6 \%$ by the cement weight (it corresponds to $1 \mathrm{wt} \% \mathrm{Al}_{2} \mathrm{O}_{3}$ ). Pyrocatechol content was $0.02 \%$ and $0.05 \%$ by the cement weight; resorcinol content was $0.05 \%$.

Mortar mixes were casted into prism (bar) moulds of $20 \times 20 \times 100 \mathrm{~mm}$ and cube moulds of $30 \times 30 \times 30 \mathrm{~mm}$. The samples were stored above water in a sealed container at $20^{\circ} \mathrm{C} \pm 2^{\circ} \mathrm{C}$ for 24 hours. After demolding samples were stored in distilled water until the compressive strength of cubic samples of at least $20 \mathrm{MPa}$ is reached (7 days). Subsequently, a zero reading of bars' length was made. After that, the bars were placed in a $5 \%$-solution of sodium sulfate and stored for 6 months at $20^{\circ} \mathrm{C} \pm 2{ }^{\circ} \mathrm{C}$; the sodium sulfate solution was replaced on a weekly basis (the solution-to-samples weight ratio in storage containers was of approx. 2.5 - 3 to 1). Measurements of bar samples' lengths were performed once every 2 weeks. Two samples were prepared for each composition and a mean value of elongation of two samples is taken as a final measurement result.

To study influence of benzenediols on the composition of test samples during their storage in sodium sulfate solution a ${ }^{27}$ Al-MAS NMR spectroscopy was used. For this purpose specimens of cement pastes were prepared by mixing cement with water at water-to-cement ratio of 0.485 ; aluminum sulfate (6 wt\%) and pyrocatechol $(0.05 \mathrm{wt} \%)$ were introduced into cement paste by preliminary dissolving in mixing water. The samples of pastes were moulded in the shape of tablets with diameter of $50 \mathrm{~mm}$ and thickness of $3-4 \mathrm{~mm}$. Storage conditions were close to ones for mortar bars-kept for 1 day above water (at relative hu- 
midity of $>90 \%)$ and then 6 more days under a thin $(\sim 3 \mathrm{~mm})$ layer of distilled water. Then each of the samples was divided into 2 parts with one piece kept in distilled water and the other piece put in 5\%-solution of sodium sulfate (liquid-to-sample weight ratio of approx. 5 to 1). Again, the sodium sulfate solution has been replaced once a week while the water left untouched. The spectral analyses were carried out on cement paste samples of 6 days of preliminary storing under water and after 1 and 2 months for both water and sodium sulfate solution stored samples. For the analysis a bit of cement paste sample $(\sim 1 \mathrm{~g})$ was thoroughly powdered in excess of acetone and vacuum-filtered; the operation has been repeated for three times to rid of any residue water. The powder was then washed with acetone on a filter paper, then filtered and vacuum-dried at ambient temperature. Prior to analysis, the samples were stored in air tight package at $-18^{\circ} \mathrm{C}$.

High-resolution solid-state ${ }^{27} \mathrm{Al}$-MAS NMR spectra have been obtained using AVANCE II-500WB (Bruker) spectrometer. Operating frequency for ${ }^{27} \mathrm{Al}$ was 130.32 MHz. Spectra were recorded by single-pulse excitation, the pulse duration of $0.7 \mu \mathrm{s}(\pi / 12)$ with a delay of $0.5 \mathrm{sec}$. was used, and number of scans was 2048. The samples material ( 100 mg) were packed in zirconia rotors (D $4 \mathrm{~mm}$ ) and rotated at $13 \mathrm{kHz}$. Chemical shifts are given in ppm relative to $\mathrm{AlCl}_{3} \cdot 6 \mathrm{H}_{2} \mathrm{O}$. The assignment of the signals is accomplished in accordance with the published data [15] [16] [17]. Signal intensities in ${ }^{27} \mathrm{Al}-\mathrm{NMR}$ spectra are given in the absolute scale (similar measurement conditions), which allows them to be compared with each other.

\section{Results and Discussion}

An evaluated setting time data of cement paste with admixtures of aluminum sulfate and benzenediols are shown in Table 1. In early period of hydration, aluminum sulfate and pyrocatechol are involved in accelerated ettringite formation or stimulate its formation; they act as set accelerators for cement pastes: aluminum sulfate at a dosage of $3 \%$ reduces the initial set to $2.5 \mathrm{~min}$ (Table 1); pyrocatechol, as is known from [5] [13], causes almost instantaneous setting of the cement paste at dosage of $0.02 \%-0.1 \%$. As is seen from Table 1 , when both aluminum sulfate and pyrocatechol are admixed simultaneously, the accelerating effect remains, but the initial set postpones up to $5 \mathrm{~min}$, which is probably due to

Table 1. Setting time of cement paste with admixtures of aluminum sulfate and benzenediols.

\begin{tabular}{ccc}
\hline & \multicolumn{2}{c}{ Time, min } \\
\cline { 2 - 3 } Admixtures & Initial setting & Final setting \\
\hline $\mathrm{Al}_{2}\left(\mathrm{SO}_{4}\right)_{3} 3 \%$ & 2,5 & 14 \\
$\mathrm{Al}_{2}\left(\mathrm{SO}_{4}\right)_{3} 3 \%$ Pyrocatechol $0.1 \%$ & 5 & 13 \\
$\mathrm{Al}_{2}\left(\mathrm{SO}_{4}\right)_{3} 3 \%$ Resorcinol $0.1 \%$ & 17 & 85 \\
\hline
\end{tabular}


the interaction between these substances. The observance of a strong plasticizing effect on cement paste, when it almost starts to free-flow, seems to confirm this proposition. This effect of pyrocatechol on cement paste rheology can be due to binding of aluminum ions into chelate pyrocatechol complexes.

Resorcinol is stated [4] to possess no properties to influence setting of Portland cement, however it was observed to increase initial and final set times remarkably when admixed along with aluminum sulfate (Table 1 ). This effect can be explained by resorcinol's ability to form complexes with Al-ions.

The results of sulfate expansion test are shown in Figure 1.

As is seen on Figure 1, the linear expansion of control mortar (curve 1) at $16^{\text {th }}$ week reaches up to about $0.3 \%$; this high rate of expansion is because of use of ordinary (not a sulfate-resisting) Portland cement and is also likely due to high water-to-cement ratio (0.485-in accordance with ASTM C 1012). The highest degree of elongation (about 3.5\%) was observed for mortar with aluminum sulfate admixture (curve 4) which indicates an intensive ettringite formation in mortar samples of such composition during their storage in sodium sulfate solution. These results correspond well with the previously published data [13]. According to the data obtained, the presence of $0.05 \%$ resorcinol and pyrocatechol in samples containing aluminum sulfate (curves 5 and 7) decreases mortar expansion rate, for pyrocatechol-all the way down to that of the reference sample. The effect of pyrocatechol on deformation is still significant enough even when its dosage is reduced to $0.02 \%$ (curve 6) while resorcinol is less efficient, which is again most likely due to its inability to form chelates with aluminum ions.

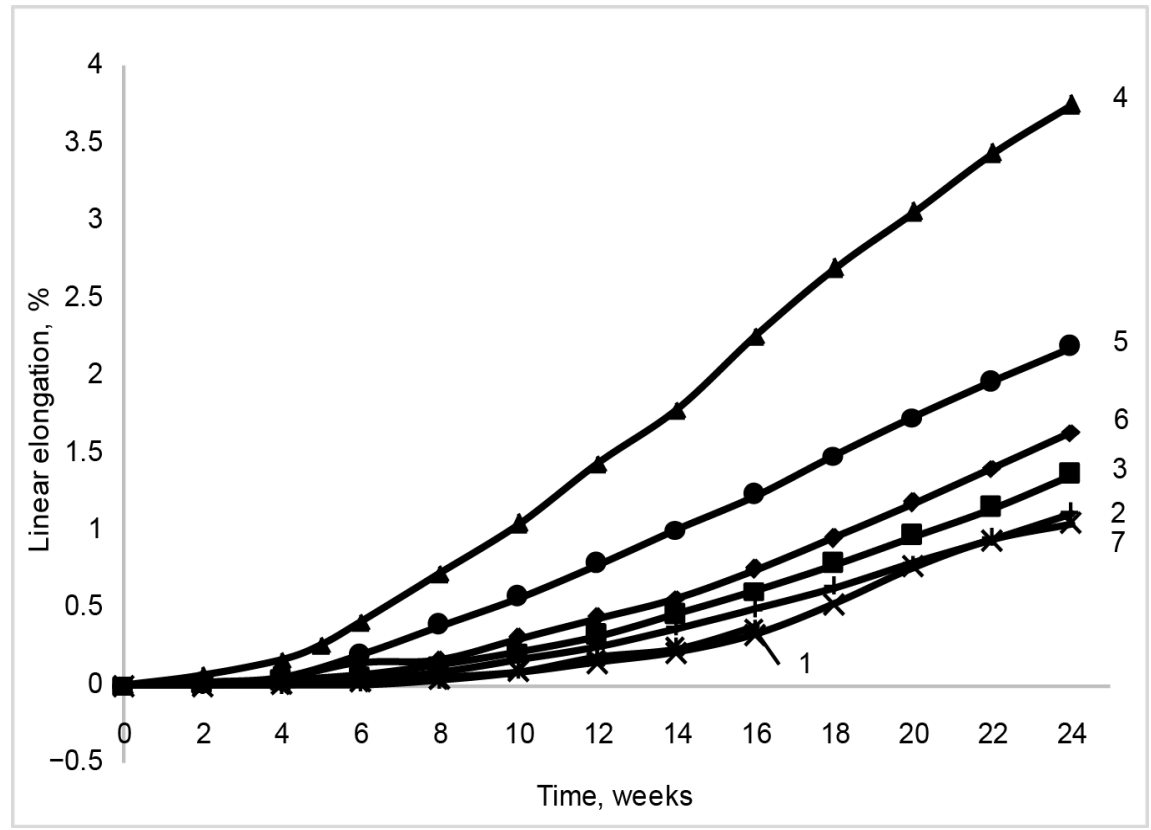

Figure 1. Linear elongation of mortar samples in sodium sulfate solution: 1-reference sample (no admixtures); 2-0.05\% resorcinol; 3-0.05\% pyrocatechol; $4-6 \% \mathrm{Al}_{2}\left(\mathrm{SO}_{4}\right)_{3}$; $5-0.05 \%$ resorcinol and $6 \% \mathrm{Al}_{2}\left(\mathrm{SO}_{4}\right)_{3} ; 6-0.02 \%$ pyrocatechol and $6 \% \mathrm{Al}_{2}\left(\mathrm{SO}_{4}\right)_{3}$; $7-0.05 \%$ pyrocatechol and $6 \% \mathrm{Al}_{2}\left(\mathrm{SO}_{4}\right)_{3}$. 
It may also be noted that the expansion curves of resorcinol (curve 2) and pyrocatechol (curve 3) mortars in absence of aluminum sulfate go in close proximity to the reference mortar (curve 1), yet both lay somewhat higher. Therefore, pyrocatechol and resorcinol are both capable to countervail partially or completely the destructive effect of aluminum sulfate, while in absence of the latter they do not seem to inhibit sulfate expansion of ordinary Portland cement on their own, but even promote mortar bars deformations slightly. This could probably be explained by polyatomic phenols exerting a leaching effect on components of C-S-H gel, which thereby increases porosity of mortars (most noticeable for pyrocatechol). It can be concluded hence that when presented together (in certain ratios) an aluminum sulfate and polyatomic phenols can extinguish each other harmful effect on cement pastes or mortars.

Figure 2 shows photos of mortar bars with 6\% aluminum sulfate and $0.05 \%$ pyrocatechol after the test has been finished. It can be seen that samples without pyrocatechol are loose, well deformed and have deep distinct cracks.

Samples with aluminum sulfate and 0.05\% resorcinol (not shown in Figure 2), despite smaller deformations in comparison to samples with aluminum sulfate alone, have a grid of shallow surface cracks especially on the tips of samples. The same is observed for samples containing both aluminum sulfate and a lesser amount $(0.02 \%)$ of pyrocatechol. Thus, with decreasing of pyrocatechol dosage from $0.05 \%$ to $0.02 \%$ its effectiveness diminishes as well.

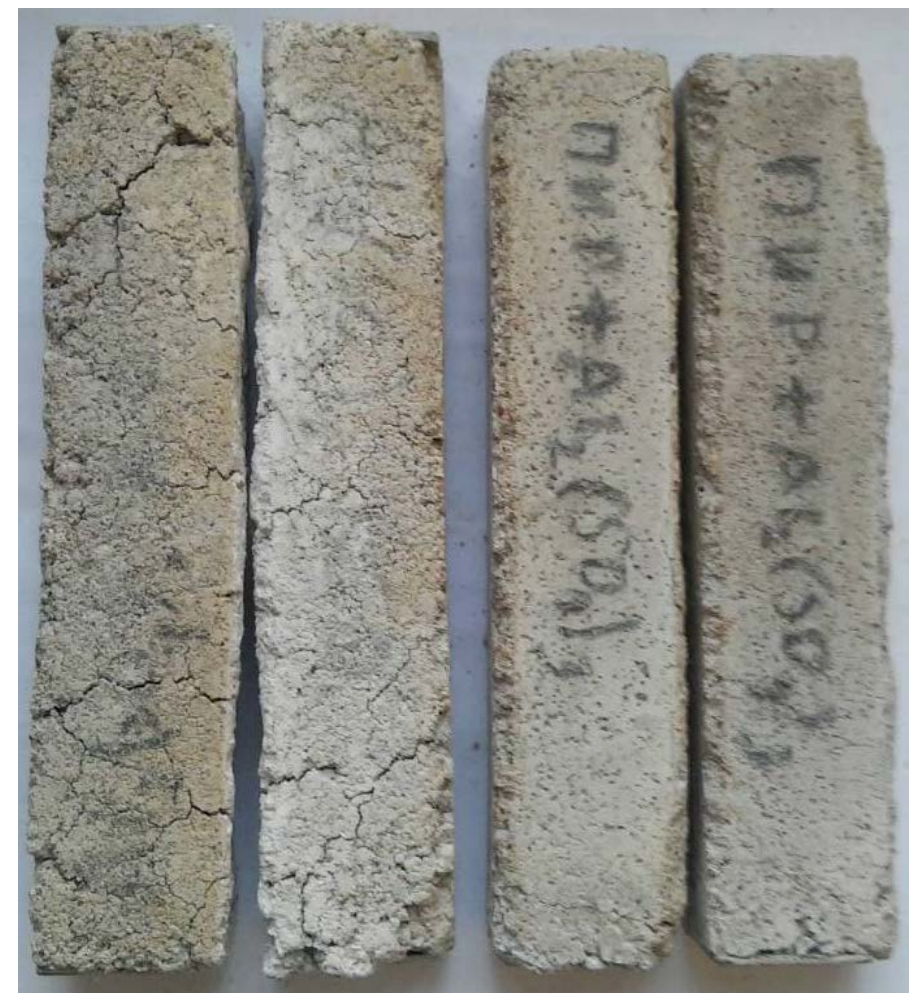

Figure 2. Mortar bars with $6 \%$ aluminum sulfate admixture after storage in a sodium sulfate solution for 6 months (two samples to the right contain additionally $0.05 \%$ pyrocatechol). 
Figure 3 shows fragments of ${ }^{27} \mathrm{Al}$-MAS NMR spectra of cement pastes with pyrocatechol and aluminum sulfate after long-term storage in distilled water and in sodium sulfate solution. Intense peaks of 6-coordinated aluminum ions of ettringite $(14.8 \mathrm{ppm})$ and calcium monosulfoaluminate $(11-12 \mathrm{ppm})$ can be observed.

As can be seen from Figure 3, the most significant differences in the spectra are due to the presence of aluminum sulfate and only to a small extent-to the presence of pyrocatechol. Thus, at the age of 7 days (Figure 3, a), the amount of ettringite in the samples with aluminum sulfate significantly exceeds the ettringite amount in two other samples. In later periods (1 and 2 months, Figure 3, b-d) the amount of ettringite in samples with aluminum sulfate is still higher than in samples of similar composition without the admixture. The amount of ettringite in samples with pyrocatechol is slightly less than in samples without it.

After prolonged underwater storage, the content of ettringite in cement paste samples is reduced due to its gradual conversion to calcium monosulfoaluminate (Figure 3, d). When stored in sodium sulfate solution, the ettringite formation in samples is recommenced and its content increases over time (Figure 3, b, c). As it is being noted before, the amount of ettringite in samples with aluminum sulfate substantially exceeds the amount of ettringite in samples without it. In contrast to these differences, the effect of pyrocatechol seems to be unimportant and has no effect on samples elongation, although it should be noted that in its presence the amount of ettringite is reduced slightly in all samples. Thus, to explain the mitigation effect of pyrocatechol, other causes should be sought rather than based on differences in delayed ettringite content. An intensive formation of delayed ettringite in mortars with aluminum sulfate is not followed by excessive deformations and cracks formation in case enough pyrocatechol is presented in mortar formulation.

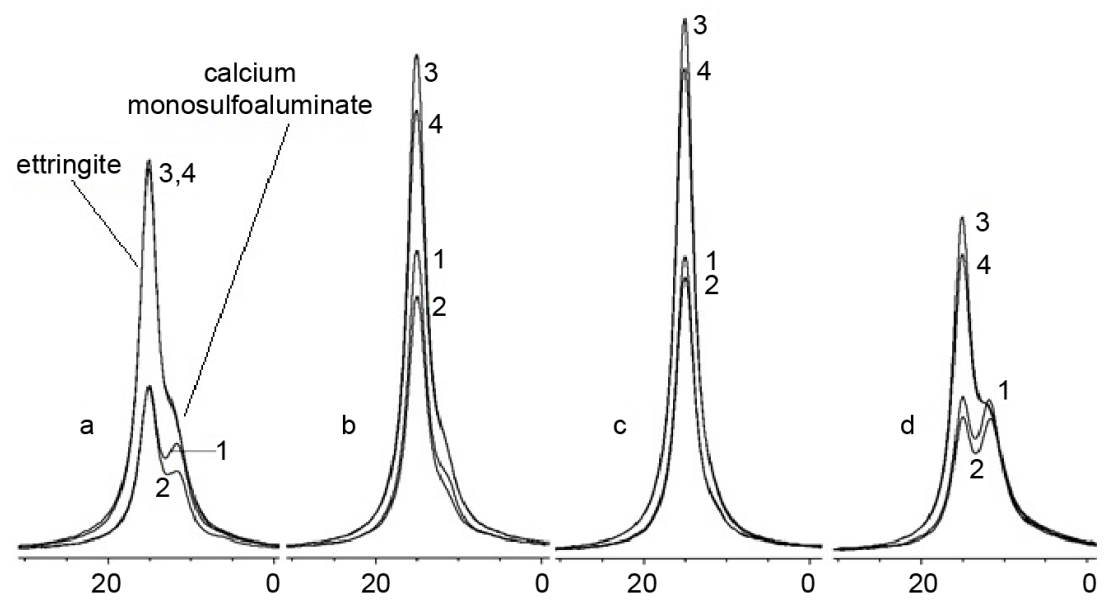

Figure $3 .{ }^{27} \mathrm{Al}$-MAS NMR spectra of cement pastes: a-at the age of 7 days (1 day-wet storage, 6 days-water storage); b, c-stored in sodium sulfate solution for 1 and 2 months, respectively; $\mathrm{d}-$ stored in water for 2 months (excluding first 7 days); 1 -pure cement paste; 2-4-with admixtures of pyrocatechol, aluminum sulfate, pyrocatechol and aluminum sulfate together, respectively. The $\mathrm{x}$-axis is the chemical shift $\delta$, ppm. 
It is known that certain mineral components of Portland cement and organic additives are able to influence morphology of ettringite crystals formed in this compositions [18] [19]. For example, in compositions based on sulfate-resisting Portland cements, an ettringite is formed with an increased content of Fe-ions ("iron-substituted" ettringite), which is believed not to cause significant internal stresses due to its structural features [18]. The ettringite morphology can be affected by some organic functional additives, for example, by polymeric plasticizers [19]. This action of organic additives is associated primarily with sorption phenomena: selective sorption of organic molecules on certain surfaces of crystal nuclei regulates the preferential growth of crystals in specified directions. Under these circumstances, it can be assumed that polyatomic phenols, and especially those with $\mathrm{OH}$-groups in ortho-position (as in case of pyrocatechol), have the ability to influence the growth of ettringite crystals. It is possible that the formation of strong chelate complexes between aluminum ions and polyatomic phenol molecules is of crucial significance. To prove this assumption additional studies required.

\section{Conclusions}

1) Benzenediols, and, notedly, pyrocatechol, inhibit propagation of destructive deformations of Portland cement mortar compositions with aluminum sulfate in case of additional intake of sulfate ions from the environment.

2) According to ${ }^{27} \mathrm{Al}-\mathrm{MAS}$ NMR data, pyrocatechol does not affect significantly the amount of ettringite formed during storage of samples in sodium sulfate solution.

3) Presumably, the ability of polyatomic phenols to suppress sulfate expansion of Portland cement mortars with aluminum sulfate admixtures is due to their impact on the ettringite crystallization which leads to the formation of ettringite that possess less destructive properties. To prove this assumption additional studies are required.

4) Pyrocatechol and resorcinol that are capable to countervail partially or completely the destructive effect of aluminum sulfate, in the absence of the latter slightly increase the development of deformations, which is due to the ability of polyatomic phenols to leach the components of the C-S-H which increases samples porosity. When aluminum sulfate and polyatomic phenols are introduced together (at certain ratios) into mortars, their destructive effects can be mutually compensated.

\section{References}

[1] Aïtcin, P.-C. and Flatt R.J. (2016) Science and Technology of Concrete Admixtures. Elsevier, Cambridge.

[2] Roberts, J.D. and Caserio, M.C. (1964) Basic Principles of Organic Chemistry. California Institute of Technology, New York.

[3] Iler, R. (1979) The Chemistry of Silica. Wiley-Interscience, New York. 
[4] Kurdowski, W. (2014) Cement and Concrete Chemistry. Springer, Dordrecht. http://www.springer.com/la/book/9789400779440 https://doi.org/10.1007/978-94-007-7945-7

[5] Justnes, H. (2010) Acceleration by Retardation in Hydration Process for Cement-Based Materials. The Journal of the Chinese Ceramic Society, 38, 1618-1622.

[6] Shapovalov, N.A, Slyusar, A.A. and Slyusar, O.A. (2003) Superplasticizer Based on Resorcinol Waste as a Thinning Additive for Ceramic Slips. Izvestia Vuzov. Stroitelstvo (News of Higher Educational Institutes. Construction), 7, 65-67.

[7] Kosukhin, M.M, Poluektova, V.A, Malinovker, V.M. and Shapovalov, N.A. (2013) Polyfunctional Superplasticizer for Concrete Based on Pyrocatechin Production Waste Products. Fundamentalnie Issledovanya (Fundamental Research), 1, 718-722. https://fundamental-research.ru/en/article/view?id=31016

[8] Dmitriev, A.A, Zlotnikov, M.G. and Tousenko, G.N. (2012) Polyfunctional Superplasticiser for Concrete Mixture and Mortar. RU Patent No 2439015.

[9] Jardine, L.A, Cornman C.N, Gupta, V. and Chun, B.W. (2006) Liquid Additive for Intergrinding Cement. US Patent No 7087110.

[10] Zivica, V. and Bajza, A. (2001) Acidic Attack of Cement-Based Materials-A Review. Part 1. Principle of Acidic Attack. Construction and Building Materials, 15, 331-340. https://doi.org/10.1016/S0950-0618(01)00012-5

[11] Zivica, V. (2006) Deterioration of Cement-Based Materials Due to the Action of Organic Compounds. Construction and Building Materials, 20, 634-641. https://doi.org/10.1016/j.conbuildmat.2005.02.011

[12] Dyer, T.D. (2011) Characterization of Two Chemical Compounds Forms between Hydrated Portland Cement and Benzene-1,2-Diol(Pyrocatechol). Journal of Materials Science, 46, 5332-5344. https://doi.org/10.1007/s10853-011-5471-2

[13] Brykov, A.S., Paritskaya, N.S. and Mokeev M.V. (2016) Effect of Pyrocatechol on Hydration of Portland Cement in the Early Period. Zement $i$ Ego Primenenie ( $\mathrm{Ce}$ ment and Its Application), 6, 80-82.

[14] Brykov, A.S, Anisimova A.V., Paritskaya N.S. and Mokeev M.V. (2015) The Impact of Aluminum- and Iron-Bearing Admixtures on the Resistance of Portland Cement Mortars to Alkali-Silica Reaction and Sulfate Attack. Materials Sciences and Applications, 6, 539-548. https://doi.org/10.4236/msa.2015.66058

[15] Andersen, M.D., Jakobsen H.J. and Skibsted J. (2004) Characterization of White Portland Cement Hydration and the C-S-H Structure in the Presence of Sodium Aluminate by ${ }^{27} \mathrm{Al}$ and ${ }^{29} \mathrm{Si}$ MAS NMR Spectroscopy. Cement and Concrete Research, 34, 857-868. https://doi.org/10.1016/j.cemconres.2003.10.009

[16] Andersen, M.D., Jakobsen, H.J. and Skibsted, J. (2006) A New Aluminium-Hydrate Species in Hydrated Portland Cements Characterized by ${ }^{27} \mathrm{Al}$ and ${ }^{29} \mathrm{Si}$ MAS NMR Spectroscopy. Cement and Concrete Research, 36, 3-17. https://doi.org/10.1016/j.cemconres.2005.04.010

[17] Rawal, A., Smith, B.J. and Athens, G.L. (2010) Molecular Silicate and Aluminate Species in Anhydrous and Hydrated Cements. Journal of the American Chemical Society, 132, 7321-7337. https://doi.org/10.1021/ja908146m

[18] Taylor, H. (1997) Cement Chemistry. 2nd Edition, Thomas Telford, London. https://doi.org/10.1680/cc.25929

[19] Shi, Ch., Zhang, G., He, T. and Li Y. (2016) Effects of Superplasticizers on the Stability and Morphology of Ettringite. Construction and Building Materials, 112, 261-266. https://doi.org/10.1016/j.conbuildmat.2016.02.198 